\title{
Resting energy expenditure and nutritional state of patients with increased oxygen cost of breathing due to emphysema, scoliosis and thoracoplasty
}

\author{
M K Sridhar, R Carter, M E J Lean, S W Banham
}

\begin{abstract}
Background - Weight loss is a well recognised feature of patients with emphysematous chronic obstructive pulmonary disease (COPD). It has been suggested that this weight loss could be due to a hypermetabolic state resulting from the increased oxygen cost of breathing (OCB). To clarify the relation between resting energy expenditure (REE), nutritional state, and OCB these indices were measured in patients with respiratory impairment and an increased OCB due to COPD, scoliosis, and thoracoplasty.
\end{abstract}

Methods - Eighteen patients (six COPD, six scoliosis, six thoracoplasty) of mean (SD) age $59.9(8.6)$ years $(8 M, 10 F)$ and six controls $(45.5(9.9)$ years; $2 M, 4 F)$ were studied. OCB was estimated by the addition of dead space to the breathing circuit and REE was measured by indirect calorimetry using a ventilated canopy system. Height, arm span, weight, triceps skin fold thickness (TSF), mid-arm muscle circumference (MAMC), forced expiratory volume in one second $\left(F E V_{1}\right)$, and vital capacity (VC) were measured in all study subjects.

Results - OCB was elevated in all patient groups (mean $7.0 \mathrm{ml} / \mathrm{l}$ ) compared with controls $(1.9 \mathrm{ml} / \mathrm{l})$. All patients with COPD, four with scoliosis, three with thoracoplasty, and none of the controls were $<90 \%$ ideal body weight. Mean (SD) measured REE as \% predicted (HarrisBenedict equation) was $103.8(7.6)$ in patients with COPD, $105.5(10.9)$ in those with scoliosis, $106.3(6.9)$ in the thoracoplasty patients, and $103.3(3.4)$ in controls. One patient with COPD, two with scoliosis, two with thoracoplasty, but no controls were hypermetabolic (REE $>110 \%$ predicted). In all groups there was a negative relation between $\mathrm{OCB}$ and lung function (OCB $v \mathrm{FEV}_{1} r=-0.83$ in COPD, -0.62 in scoliosis, -0.67 in thoracoplasty, and -0.76 in controls). There was no correlation between REE and OCB or MAMC.

Conclusions - In patients with respiratory disease OCB (augmented ventilation) is related to lung function but not to REE. This is evidence against the hypothesis that hypermetabolism due to increased oxygen cost of breathing at rest is the sole or major cause of malnutrition in patients with lung disease.

(Thorax 1994;49:781-785)

Weight loss and malnutrition are well recognised features of patients suffering from emphysematous chronic obstructive pulmonary disease (COPD). ${ }^{12}$ While it is known that malnutrition is an adverse prognostic feature, the reason for its occurrence in these patients remains unclear. ${ }^{3}$ Malnourished patients with COPD have been shown to have an elevated resting energy expenditure (REE) and it has been suggested that an increase in the oxygen cost of breathing (OCB) results in a state of negative energy balance and weight loss. ${ }^{4-6}$ However, this conventional hypothesis has been challenged by recent findings. Ryan et $a l$ in a study of energy balance in malnourished patients with COPD showed that, like other malnourished individuals, they have a low rather than a high resting energy expenditure (REE) and are therefore hypometabolic rather than hypermetabolic. ${ }^{7}$ Moreover, other investigators have shown that even well nourished patients with COPD demonstrate an elevated resting oxygen consumption. ${ }^{8}$

To determine whether an increased OCB is associated with an elevated REE and malnutrition, and to explore the relation between REE, OCB, lung function, and nutritional status, we have measured these parameters in patients with respiratory impairment due to COPD and in patients with scoliosis and thoracoplasty who also exhibit an increase in the energy cost of breathing. ${ }^{9}$

\section{Methods}

PATIENTS

Six patients with COPD ( $3 \mathrm{M}, 3 \mathrm{~F}$; mean (SD) age $67 \cdot 0(3 \cdot 0)$ years), six with scoliosis (3M, $3 \mathrm{~F} ; 51 \cdot 0(7 \cdot 2)$ years), and six with thoracoplasty (2M, 4F; $61.7(5 \cdot 7)$ years) were studied. All were in a clinically stable state, free from overt oedema and signs of respiratory tract infection. All the patients with COPD and five of those with thoracoplasty were receiving inhaled $\beta$ agonists. All the patients with COPD, four with thoracoplasty, and two with scoliosis were exsmokers. Six non-smoking healthy volunteers (2M, 4F; $45.5(9.9)$ years) were also studied in order to assess the reliability of the various techniques used in the study. 
The study was approved by the local ethical committee and the patients gave their informed consent to the investigations.

\section{NUTRITIONAL MEASURES}

Body height was measured to the nearest $0.5 \mathrm{~cm}$ with the patient standing barefoot. In scoliotic patients the arm span was used in lieu of height. ${ }^{10}$ Body weight was measured to the nearest $0.1 \mathrm{~kg}$ by a beam scale (Weylux Model 424, UK) and expressed as percentage predicted of ideal body weight. ${ }^{11}$ Triceps skin fold thickness (TSF) was measured to the nearest $0.2 \mathrm{~mm}$ by Holtain skin fold calipers using the standard technique. ${ }^{12}$ Mid-arm circumference (MAC) was measured and mid-arm muscle circumference (MAMC) derived from the formula MAMC $=$ MAC $-3 \cdot 14\{$ TSF $\}$. TSF and MAMC were compared with normal values and expressed as percentage predicted. ${ }^{13}$

\section{RESTING ENERGY EXPENDITURE (REE)}

REE was measured by open circuit indirect calorimetry in all subjects using a ventilated canopy system (Deltatrac Metabolic Monitor, Datex Instrumentarium, Helsinki, Finland) on an outpatient basis after an overnight fast of at least 10 hours. Measurements were made with the subjects in the semirecumbent posture at least two hours after the last dose of medication in patients on $\beta$ agonists. After a rest period of 30 minutes oxygen consumption $\left(\mathrm{Vo}_{2}\right)$, carbon dioxide production $\left(\mathrm{V}_{\mathrm{CO}_{2}}\right)$, and respiratory quotient $(R Q)$ were estimated every minute for a period of 20 minutes. The data obtained in the first five minutes were discarded and data obtained in the last 15 minutes were used to estimate REE if there was less than $5 \%$ minute to minute variation in the $\mathrm{RQ}$ and $\mathrm{Vo}_{2}$. REE was calculated using Weir's formula. ${ }^{14} \mathrm{Gas}$ calibration was performed before each measurement with a standard high purity gas mixture provided by the manufacturer. The system was checked by a methanol burning test every week during the study period and the average $R Q$ values for the last 15 minutes of a 30 minute methanol burning run were confirmed to be within 0.64 and 0.69 . Flow calibration was also performed by calculating the total amount of carbon dioxide produced during the methanol burning test and the flow constant adjusted if appropriate. The reproducibility of the technique was established by a pilot study on 10 patients studied on separate occasions in the fasting state. The coefficient of variation for measurements of $\dot{\mathrm{V}} \mathrm{O}_{2}$ and $\dot{\mathrm{VCO}}_{2}$ were between $3 \%$ and $8 \%$.

\section{OXYGEN COST OF BREATHING (OCB)}

OCB was measured by the method described by Cherniack. ${ }^{15}$ Expired gas was collected via a mouthpiece attached to a low dead space valve and passed through to a metabolic measurement cart (Benchmark System, PK Morgan, UK). The cart measures ventilation by a flexible membrane flow meter. Oxygen and carbon dioxide tensions are measured with a zirconia crystal and a rapid infrared analyser respectively. At the beginning and end of each measurement the gas analysers were calibrated using a high purity gas mixture (BOC, UK). Accuracy of the flow measurements were confirmed to be within $2 \%$ over a range of flow rates. Resting $\mathrm{VO}_{2}$ and minute ventilation ( $\dot{\mathrm{VE}}$ ) were measured first for 15 minutes using the metabolic cart and the data obtained during a five minute period of stable ventilation (minute to minute variation in ventilation $<1$ litre) were used in the calculations. Following this a 15 minute rest period of breathing without the mouthpiece was allowed. The subject was again attached to the mouthpiece, now with a dead space tubing added to the breathing circuit. The volume of the dead space added was variable and aimed to increase the subject's minute ventilation by 5-10 litres. Once a stable level of ventilation had been achieved with the dead space, $\dot{\mathrm{Vo}}_{2}$ and $\dot{\mathrm{VE}}$ were estimated again over a stable period. Oxygen cost (in $\mathrm{ml} / \mathrm{l}$ ventilation) was defined as the ratio of the increase in the oxygen consumption between the dead space and resting ventilation relative to the increase in minute ventilation. The coefficient of variation for $\dot{\mathrm{VO}}_{2}$ measurements with added dead space, based on a study of 10 patients on separate occasions, was between $6 \%$ and $11 \%$. It was felt that, given the relative unpredictability of a patient's response to dead space breathing, this was an acceptable level of variability and could not be improved upon any further by refinements of this particular technique.

\section{PULMONARY FUNCTION}

Forced expiratory volume in the first second $\left(\mathrm{FEV}_{1}\right)$ and vital capacity (VC) were measured using a whole body plethysmograph (PK Morgan, Rainham, UK) and expressed as a percentage of predicted values. ${ }^{16}$

\section{STATISTICAL METHODS}

Data were analysed using the MINITAB statistical programme (Clecom, Birmingham, UK). Comparison between the patient groups was by analysis of variance. Correlation between variables was determined in each group by Pearson product moment correlation coefficient. Linear regression equations were developed using stepwise regression analysis. REE was used as the dependent response variable, and body weight, lung function, and OCB as independent explanatory variables. Significance was assessed at the $5 \%$ level.

\section{Results}

ANTHROPOMETRIC MEASURES AND PULMONARY FUNCTION (table 1)

All patients in the COPD group, four in the scoliosis group, and three in the thoracoplasty group were less than $90 \%$ ideal body weight. Comparison between the three patient groups by analysis of variance showed no significant difference in any of the measures except vital capacity. 
Table 1 Mean (SD) anthropometric and pulmonary function data

\begin{tabular}{|c|c|c|c|c|c|}
\hline & $C O P D$ & Scoliosis & Thoracoplasty & Controls & $\begin{array}{l}\text { Analysis of variance } \\
\text { between patient } \\
\text { groups ( } p \text { value) }\end{array}$ \\
\hline $\begin{array}{l}\% \text { IBW } \\
\text { TSF (\% pred) } \\
\text { MAMC (cm) } \\
\text { MAMC (\% pred) } \\
\text { FEV }_{1}(\% \text { pred) } \\
\text { VC (\% pred) }\end{array}$ & $\begin{array}{lr}77 \cdot 1 & (7 \cdot 8) \\
37 \cdot 7 & (20 \cdot 8) \\
18 \cdot 7 \quad(2 \cdot 1) \\
74 \cdot 8 & (2 \cdot 6) \\
34 \cdot 3 & (8 \cdot 8) \\
66 \cdot 1 & (15 \cdot 2)\end{array}$ & $\begin{array}{l}94 \cdot 5(26 \cdot 6) \\
70 \cdot 0(31 \cdot 7) \\
19 \cdot 3(3 \cdot 1) \\
77 \cdot 8(6 \cdot 6) \\
29 \cdot 8(12 \cdot 4) \\
30 \cdot 2(12 \cdot 4)\end{array}$ & $\begin{array}{l}91.0(21 \cdot 1) \\
81.3(38.9) \\
19.9(2 \cdot 0) \\
77.5(10 \cdot 5) \\
35.6(12 \cdot 4) \\
42.3(6.6)\end{array}$ & $\begin{array}{r}106 \cdot 2(3 \cdot 5) \\
94 \cdot 8(8 \cdot 0) \\
23 \cdot 0(3 \cdot 8) \\
93 \cdot 9(7 \cdot 1) \\
95 \cdot 6(6 \cdot 2) \\
100 \cdot 2(4 \cdot 3)\end{array}$ & $\begin{array}{r}0.32 \\
0.17 \\
0.72 \\
0.74 \\
0.65 \\
<0.01\end{array}$ \\
\hline
\end{tabular}

$\mathrm{IBW}=$ ideal body weight; $\mathrm{TSF}=$ triceps skinfold thickness; $\mathrm{MAMC}=$ mid-arm muscle circumference; $\mathrm{FEV}_{1}=$ forced expiratory volume in one second; $\mathrm{VC}=$ vital capacity.

RESTING ENERGY EXPENDITURE (fig 1)

REE was greater than $10 \%$ of predicted values (Harris-Benedict equation ${ }^{17}$ ) in one patient with COPD, two with scoliosis and two with thoracoplasty. All controls had REE within $10 \%$ of the predicted values. There was no significant difference in the fasting $R Q$ values of the various groups. The hypermetabolic patients also did not differ in terms of drug therapy or smoking status from the patients whose REE was within the normal range.

OXYGEN COST OF BREATHING (table 2)

OCB was three or four times higher in the patient groups than in the controls. Analysis of variance showed no significant difference between patient groups.

OXYGEN COST AND LUNG FUNCTION (fig 2)

There was a negative relation between $\mathrm{OCB}$ and $F E V_{1}$ and between $O C B$ and VC in all patient groups. The correlation was significant at the $5 \%$ level in the patients with COPD.

\section{OXYGEN COST AND REE}

There was no relation between OCB and REE $(r$ values for OCB $v$ REE: $\mathrm{COPD}=0 \cdot 15$; thoracoplasty $=-0.62$; scoliosis $=0.41$; controls $=0 \cdot 56$ ).

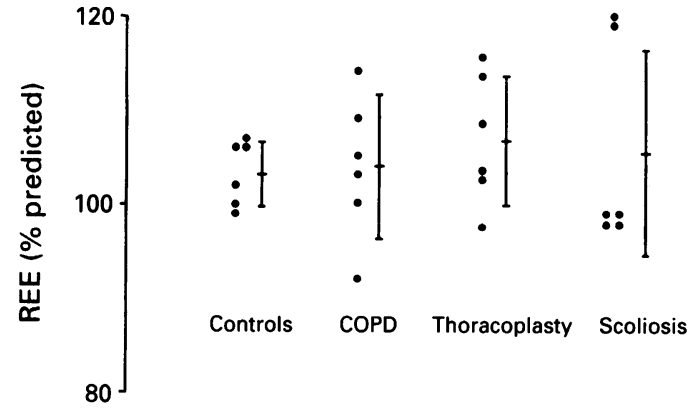

Figure 1 Resting energy expenditure (REE) as \% predicted by Harris-Benedict equation in the various study groups.

Table 2 Mean (SD) oxygen cost of breathing (OCB) data

\begin{tabular}{|c|c|c|c|c|}
\hline & $\begin{array}{l}\text { Controls } \\
(n=6)\end{array}$ & $\begin{array}{l}C O P D \\
(n=6)\end{array}$ & $\begin{array}{l}\text { Scoliosis } \\
(n=6)\end{array}$ & $\begin{array}{l}\text { Thoracoplasty } \\
(n=6)\end{array}$ \\
\hline $\begin{array}{l}\text { Resting } \mathrm{VE}(1 / \mathrm{min}) \\
\text { Resting fR (breaths/min) } \\
\mathrm{OCB}\left(\mathrm{ml} \mathrm{O} \mathrm{O}_{2} / 1 \text { ventilation) }\right.\end{array}$ & $\begin{array}{r}6 \cdot 7(1 \cdot 7) \\
10 \cdot 7(1 \cdot 8) \\
1.9(2 \cdot 0)\end{array}$ & $\begin{array}{r}7 \cdot 9(1 \cdot 3) \\
12 \cdot 3(2 \cdot 0) \\
6 \cdot 5(1 \cdot 3)\end{array}$ & $\begin{array}{r}6.5(1.6) \\
13.5(1.4) \\
7.6(1 \cdot 1)\end{array}$ & $\begin{array}{r}6.5(1.4) \\
12 \cdot 8(1 \cdot 9) \\
7 \cdot 0(2 \cdot 0)\end{array}$ \\
\hline
\end{tabular}

$\dot{V} E=$ minute ventilation; $f R=$ breathing rate $\mathrm{OCB}=$ oxygen cost of breathing.
There was no correlation between REE and indicators of nutritional status (TSF or MAMC) in any of the groups.

On multiple regression body weight alone accounted for over $80 \%\left(r^{2}=83.6\right)$ of the variation in measured REE.

\section{Discussion}

The relation between REE, lung function, oxygen cost of breathing, and malnutrition in patients with lung disease (particularly COPD and cystic fibrosis) has been the focus of much attention in recent years. ${ }^{4-618}$ Studies have shown that both well nourished and malnourished patients may be hypermetabolic, ${ }^{4519}$ but there is no conclusive evidence that hypermetabolism is a universal feature in malnourished patients with COPD. ${ }^{720}$ In our study only five of 18 patients with different types of respiratory impairment (COPD, chest wall disease) exhibited an elevated REE. Oxygen cost of breathing was raised in line with deteriorating lung function, but was not always associated with an elevation in REE. Moreover, there was no consistent relation between REE, $\mathrm{OCB}$, and indicators of nutritional status. Our study thus adds support to the view that the increased work of breathing is not always accompanied by an elevated REE, and that a high OCB in itself is unlikely to account for the poor nutritional status of patients with lung disease.

The reasons for the differences in the results of our study and those of Donahoe $e t a l^{4}$ and Goldstein $e t a l^{19}$ are probably methodological. Firstly, we used a non-invasive system to measure REE in order to circumvent the effect of respiratory apparatus on the breathing pattern. ${ }^{21}$ In a previous study of similar patients we have shown that there is a significant difference in the REE estimated by the ventilated canopy and mouthpiece plus nose clip systems, with the latter consistently tending to overestimate the REE. ${ }^{22}$ Secondly, our patients were all studied in the fasting state early in the morning, unlike those of other workers whose patients were studied at various times of the day whilst on an intravenous infusion of nutrients. ${ }^{19}$

Although it is known that the work of breathing is increased in patients with chest wall disease, ${ }^{9}$ there are no precise data in the literature regarding their actual oxygen cost of breathing. Since the values for $\mathrm{OCB}$ in patients with COPD obtained in this study $(6.5(1 \cdot 3)$ $\mathrm{ml} / \mathrm{l})$ match well with studies by Cherniack ${ }^{15}$ 

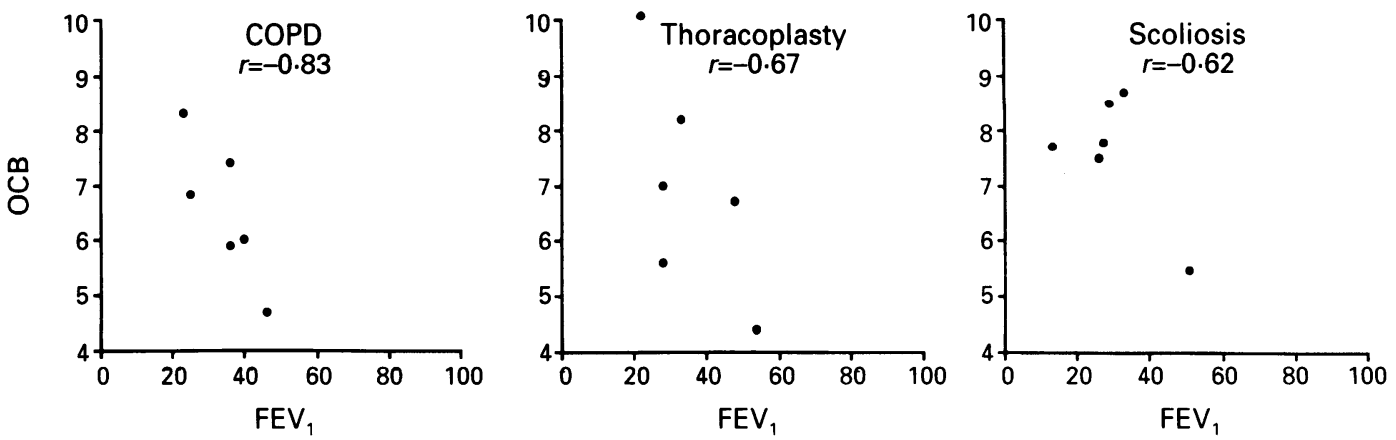

$\%$ predicted FEV
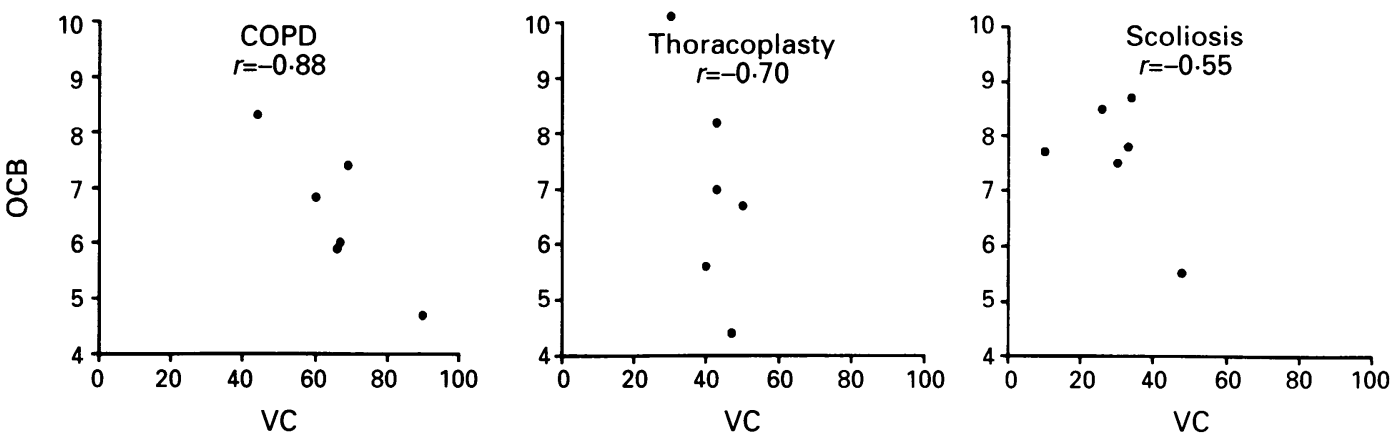

$\%$ predicted VC

Figure 2 Relation between oxygen cost of breathing (OCB) and indices of lung function (forced expiratory volume in one second $\left(F E V_{1}\right)$ and vital capacity $\left.(V C)\right)$ in the three patient groups.

$(5.96 \mathrm{ml} / \mathrm{l})$ and Levinson and Cherniack ${ }^{23}$ $(6.3 \mathrm{ml} / \mathrm{l})$, we believe that our methods are reliable and compare with those of previous investigators. Our study of the OCB of patients with chest wall disease and COPD leads us to conclude that in both these patient groups OCB is elevated in line with their respiratory dysfunction.

Whilst our techniques and methodology seem reliable (as demonstrated by the results of studies on controls), our study as a whole suffers from some limitations. This study, like most others in this field, is small and this limits the power of statistical analysis. For example, whilst the correlation between OCB and lung function for the study population as a whole $(\mathrm{n}=24)$ is strikingly significant (OCB $v \mathrm{FEV}_{1}$, $r=0.87$ ), because of the small numbers in each group $(n=6)$ correlations in each group, while showing a consistent negative trend, do not reach significance except in patients with COPD. In our group of 18 severely disabled patients only five were found to be hypermetabolic. A greater number of such patients would have allowed a valuable comparison of patients with normal and elevated REE irrespective of underlying disease. It is also uncertain whether the cost of augmenting ventilation can be taken to be the cost of resting ventilation, especially in patients who may find it difficult to augment their ventilation. It is certainly possible that the oxygen cost of resting ventilation is not particularly different in patient groups and that the OCB rises at different rates with increasing ventilation. Thus the differences in the oxygen cost of augmenting ventilation need not represent a difference in the oxygen cost of resting vent- ilation. Similar criticisms would apply to the other studies in this field. ${ }^{4523}$

The unreliability of various anthropometric measures in patients with chest wall deformities (scoliosis and thoracoplasty) pose certain problems that merit mention. The Harris-Benedict equation uses the age, sex, height, and weight of subjects to calculate REE. In our patients with skeletal deformities height could not be used as a measure of body dimension and arm span was used instead. It is worth pointing out that the use of the Schofield equation ${ }^{24}$ - which is based on weight, age, and sex - did not alter the results. The presence of thoracic cage deformities rendered measurement of subscapular and suprailiac skinfold thickness unreliable, making anthropometric estimation of body composition difficult. We had proposed measuring body composition by underwater weighing ${ }^{25}$ but this technique did not find favour with the patients and was not pursued. We are thus unable to provide potentially useful data on the body composition of the various patient groups and its relation to their REE.

If the increased cost of resting ventilation does not account for weight loss, what then might be the reason for this finding in patients with COPD? Malnutrition in patients with COPD is related more to impaired gas exchange (as evidenced by a low diffusing capacity for carbon monoxide) than to airflow obstruction. ${ }^{3}$ The impaired gas exchange results from loss of the pulmonary capillary bed and might well result in an inability to augment cardiac output in response to the stress of even minimal effort, leading to lack of oxygen delivery to the tissues and nutritional depletion. Filley and coworkers ${ }^{26}$ have shown that "pink 
puffers" suffer from an inability to augment cardiac output compared with "blue bloaters." Further studies in this regard may be of interest. Another hypothesis postulates that a stepped decline in weight and lung function is precipitated by acute illnesses including infective exacerbations. ${ }^{3}$

Our study has shown that the increased oxygen cost of augmented ventilation in clinically stable patients with respiratory disease is inversely related to lung function. No consistent relation could be found between oxygen cost of augmented ventilation, resting energy expenditure, and nutritional status in these patients. We conclude that it is unlikely that the increased oxygen cost of resting ventilation is the sole or major cause of malnutrition in patients with lung disease.

The authors with to thank Dr Adrian Bowman, Senior Lecturer, Department of Statistics, University of Glasgow for his comments on the statistical analysis.

1 Wilson DO, Rogers RM, Wright EC, Anthonisen NR. Body weight in chronic obstructive pulmonary disease: the $\mathrm{Na}$ tional Institute of Health intermittent positive pressure tional Institute of Health intermittent positive pressur
breathing trial. Am Rev Respir Dis 1989;139:1435-8.

2 Openbrier DR, Irwin MM, Rogers RM, Gottleib GP, Dauber JH, Vantheil $\mathrm{OH}$, et al. Nutritional status and lung function in patients with emphysema and chronic bronchitis. Chest 1983;83:17-22.

3 Wilson DO, Rogers RM, Hoffman RM. Nutrition and chronic lung disease. Am Rev Respir Dis 1985;132:134765.

4 Donahoe M, Rogers RM, Wilson DO, Pennock BE. Oxygen consumption of the respiratory muscles in normal and malnourished patients with chronic obstructive pulmonary disease. Am Rev Respir Dis 1989;140:385-91.

5 Schols AMWJ, Fredrix EFHM, Soeters PB, Westerterp KR, Wouters EFM. Resting energy expenditure in patients with chronic obstructive pulmonary disease. Am $\mathcal{F}$ Clin Nutr 1991;54:983-7.

6 Fitting JW, Frascarlo P, Jequier E, Luenberger P. Energy expenditure and rib-cage abdominal motion in chronic obstructive pulmonary disease. Eur Respir F 1989;2:840-5.

7 Ryan CF, Road JD, Buckley PA, Ross C, Whittaker JS Energy balance in stable patients with chronic obstructive pulmonary disease. Chest 1993;103:1038-44.
8 Lanigan C, Moxham J, Ponte J. Effect of chronic airflow obstruction on resting oxygen consumption. Thorax 1990 45:388-90.

9 Bergofsky EH. Respiratory failure in disorders of the thoracic cage. Am Rev Respir Dis 1979;119:643-69.

10 Branthwaite MA. Cardiorespiratory consequences of unfused idiopathic scoliosis. Br $\mathcal{F}$ Dis Chest 1977;71:145-67.

11 Metropolitan Life Insurance Company weight standards for men and women. New York: Metropolitan Life, 1983.

12 Durnin JVGA, Rahaman MM. The assessment of the amount of fat in the human body from measurement of skinfold thickness. Br $\mathcal{F}$ Nutr 1967;21:681.

13 Bishop CW, Bowen PE, Richey SJ. Norms for nutritional assessment of American adults by upper arm anthropometry. Am $\mathcal{F}$ Clin Nutr 1981;34:2530-9.

14 Weir JB. New methods for calculating metabolic rate with special reference to protein metabolism. f Physiol 1949; 109:1-9.

15 Cherniack RM. The oxygen consumption and efficiency of the respiratory muscles in health and emphysema. $f$ Clin Invest 1959;134:347-52.

16 Grimby G, Soderholm B. Spirometric studies in normal subjects III. Static lung volumes and maximal voluntary ventilation in adults with a note on physical fitness. Acta Med Scand 1963;173:199-206.

17 Harris JA, Benedict FG. Biometric studies of basal metabolism in man. Washington, DC: Carnegie Institute, 1919 (publication no. 27A).

18 Naon H, Hack S, Shelton MT, Gotthoffer RC, Gozal D. Resting energy expenditure. Evolution during antibiotic treatment for pulmonary exacerbation of cystic fibrosis. Chest 1993;103:1819-25.

19 Goldstein S, Askanazi J, Weissman C, Thomshaw B, Kinney JM. Energy expenditure in patients with chronic obstructive pulmonary disease. Chest 1987;91:222-4.

$20 \mathrm{Green} \mathrm{JH,} \mathrm{Muers} \mathrm{MF.} \mathrm{Comparison} \mathrm{between} \mathrm{basal} \mathrm{metabolic}$ rate and diet induced thermogenesis in different types of chronic obstructive pulmonary disease. Clin Sci 1992;83: chronic

21 Ashkenazi J, Silverberg PA, Foster RJ, Hyman AI, Millic Emili J, Kinney JM. Effects of breathing apparatus on breathing pattern. 7 Appl Physiol 1980;48:577-80.

22 Sridhar MK, Lean MEJ, Banham SW. Estimation of resting energy expenditure (REE) in patients with chronic lung disease: comparison of a ventilated hood and mouthpiece disease: comparison of a ventilat

23 Levinson $H$, Cherniack RM. Ventilatory cost of exercise in chronic obstructive pulmonary disease. $\mathcal{f}$ Appl Physiol 1968;25:21-7.

24 Schofield WN. Predicting basal metabolic rate, new standards and review of previous work. Hum Nutr Clin Nutr 1985;39c(Suppl 1):5-41.

25 Lukaski HC. Methods for the assessment of human body composition: traditional and new. Am F Clin Nutr 1987; 46:537-56.

26 Filley G, Beckwitt H, Reeves J, Mitchell R. Chronic obstructive bronchopulmonary disease. Am $\mathcal{F}$ Med 1968;44: 26-38. 